\section{TOBACCO GOES UNDER THE COUNTER IN WALES}

Big shops and supermarkets in Wales are now banned from displaying tobacco products under a new law which came into force in England earlier this year. The ban in Wales was announced just as international news reported that branding is to be removed from tobacco products altogether in Australia, and replaced with graphic images and health warnings.

In England and Wales, businesses breaking the law on tobacco displays could be fined up to $£ 5,000$ or jailed for up to two years. Unbranded price lists will be displayed at tills. Illustrated lists will be available upon request following an ID check. The ban will include smaller shops and specialist tobacconists in April 2015.

Australia is the first country to remove branding from all tobacco products and the UK Government has been consulting over whether to follow suit in attempts to further reduce the number of people who smoke and take up smoking. The British Dental Health Foundation has lobbied for plain packaging for a number of years and welcomed the news of Australia 'setting a precedent'.

\section{By Laura Pacey}

\title{
RIGHT TO SMILE AND SEE THE BILL FIRST
}

The Office of Fair Trading (OFT) has launched a new campaign to help patients understand more about their rights.

The 'Right to Smile' campaign, supported by the British Dental Association (BDA), private dentistry providers and a number of consumer groups, has been launched to help patients make informed decisions, understand more about their entitlements to NHS treatment, and know what their options are if things go wrong.

The OFT advises that regardless of whether patients have an NHS or private dentist they should receive a written treatment plan which includes the cost of any treatment their dentist has discussed with them. As part of the campaign the OFT has released a film and produced an information leaflet.

Dr Martin Fallowfield, the Chair of the BDA's Principal Executive Committee, said: 'As the OFT acknowledges, patients' satisfaction with dental care in the UK is very high. Effective communication between dentists and patients is vital in improving oral health and the BDA is pleased to lend its support to this campaign.' www.oft.gov.uk/OFTwork/ consumer-protection/campaign 11-12/dentistry/;jsessionid $=\mathrm{D} 304789012816548$ AD8375865 F2D8F20

\section{HONOURS, AWARDS, APPOINTMENTS}

\author{
Certificate of Merit \\ In October the Pierre Fauchard Academy awarded a \\ certificate of merit to Russ Ladwa, general dental \\ practitioner and BDA PEC member, for distinguished \\ contribution to the profession of dentistry.
}

\section{Honorary Doctorate \\ Professor Stephen Porter, Director of the UCL Eastman Dental Institute, has received an Honora ry Doctorate in Medicine by the University of Gothenburg, Sweden, in recognition of his significant achievements allied to international oral medicine.}

Best start-up

SS Dental Services, dental engineers, based in Plymouth, have won an award for best start-up company in the South West at the South West Biomedical iNet's second Innovation Award Ceremony in Bristol.

Inaugural chair

Dr Jim Lafferty, a dentist in Sheffield, has been elected as the inaugural Chair of the BDA's new English Council. The English Council exists to advise the BDA Principal Executive Committee (PEC) on all matters relating to policy in England, and to liaise with BDA's branches and sections.

\section{Accreditation award \\ Dorset HealthCare is the first individual dental service in the UK to receive University Practice Development Accreditation (UPDA). The award was presented to the dental team at the official opening of a new special care dental clinic in Bournemouth in October.}

\section{BSDHT President}

Dental hygienist Julie Rosse is the new President of the British Society of Dental Hygiene and Therapy (BSDHT); successor to Sally Simpson. Ms Rosse had held the post of President Elect since 2010.

\section{BDA Scotland Director}

Pat Kilpatrick has been appointed as the new Director of the BDA for Scotland. She will take up her post next month and brings to the post extensive experience in the healthcare sector including operational and strategic management and postgraduate teaching and research.

\section{FIRST FACIAL PALSY CHARITY LAUNCHES}

The first ever worldwide charity dedicated to facial paralysis has launched in the UK. Facial Palsy UK has been set up by experts in the field to promote better understanding about facial palsy, to raise funds for research into its causes and treatments, and to provide support for patients living with the condition.

Over 100,000 people in the UK suffer with facial palsy due to myriad causes including cancer, injury, neurological conditions, strokes or syndromes, and patients in the UK take on average almost six years from presenting symptoms to the start of treatment.

According to consultant plastic surgeon and chairman of Facial Palsy UK's medical advisory board, Charles Nduka, the charity has been launched to improve the quality for those living with facial paralysis: 'Problems faced include delayed diagnosis, a lack of awareness of suitable treatments amongst some health professionals, and a poor appreciation of the psycho-social implications of losing the ability to smile and the use of one side of the face. Facial palsy is not a "cosmetic" but a functional problem affecting important activities such as eating, drinking and protecting the eye.' www.facialpalsy.org.uk 